the International Council of Museums in London on the place of natural history museums in the natural sciences and in the general cultural life of the community. The paper was published in the Museums Journal (November 1950). Dr. Parr maintained that the very great developments in physiology, experimental biology and other subjects not dependent upon museums naturally altered their function in the world of science. The introduction of zoological gardens, photography and the cinema have created other media for depicting Nature which did not exist when the arrangement in museums was determined. It is rightly maintained that the needs of the specialist and the demands for the education of the public are basically different. In relation to research it is essential that some type of intelligently planned and sensibly executed division of labour should be arranged so that the specialist will not need to waste so much of his time tracing material sources. In this connexion it would be natural for each institution to concentrate its efforts on becoming a complete source, in material and information, for its own region. In addition, the larger institutions should, by agreement, be responsible for particular divisions of the natural sciences. In the designated subject their collections should be as complete as possible. It is also necessary for museums to emphasize that they deal not only with the form of the dead but also with the life of the living. They are rapidly becoming the chief centres of ecological research. From the point of view of the average member of the public, it is true to state that he is not so much interested in undisturbed or wild life as it exists in Nature, but rather in the environment of man. This then is the field in which the educational efforts of the natural history museums should make their greatest contribution to human thought, welfare and progress to-day. This stimulating paper by Dr. Parr is commended to specialists as well as those interested in the visual education of the community.

\section{Bibliography of Political, Economic and Social Aspects of Atomic Energy}

IN 1949, the Atomic Energy Commission Group of the Department of Security Council Affairs (United Nations Organization) issued a printed edition of "An International Bibliography on Atomic Energy. Vol. 1 : Political, Economic and Social Aspects", of which preliminary versions had appeared "earlier as mimeographed documents. Several important books and articles reflecting individual views and public discussion, in addition to a series of United Nations documents, have appeared since, and these have necessitated a supplement to Vol. 1 (Supplement No. I. Pp. v+22. Lake Success, N.Y.: United Nations; London: H.M. Stationery Office, 1950. 1s. 9d.). This supplement deals with the literature in the English and Russian languages published during the period March 1949-June 1950, inclusive. It is hoped to issue at a later date a new edition of the bibliography incorporating additional, as well as the present, material. In the contents, 275 separate items are listed under the following headings : international control ; national control and development ; peaceful uses of atomic energy; military uses and defence measures; social, economic, political and ethical implications; and general descriptions of atomic physics. Each item contains the name of the author, the original title (with a translation if in a foreign language) and the reference, and in most cases a summary or quotation from the article. The historian, the social scientist, and those interested in the technical aspects of nuclear energy and civil defence will find the bibliography most interesting and useful.

\section{Fracture of Metals}

THE refresher courses organized by the Institution of Metallurgists have obtained a high reputation. Until 1949, however, these lectures were not published; but those given at the course in that year on "The Fracture of Metals" have been published by the Institution (pp. 138; 12s.6d.) and form an admirable summary of knowledge regarding such fracture under all the main conditions of service. Of the six papers included in this volume the first, by Dr. N. P. Allen, of the National Physical Laboratory, provides a most excellent summary of fundamental knowledge regarding cohesion and rupture in metals. It is a curious fact that our knowledge of the circumstances in which metals break is considerably less than that regarding those at which plastic yielding sets in, and of the conditions which lead to ductile or brittle frecture, respectively, knowledge is at present highly imperfect. With this paper as a background, the others deal with specific aspects of the problem of a more practical and engineering nature. Dr. R. W. Bailey discusses fracture due to creep, and H. L. Cox rupture under fatigue. The effect of stress corrosion in leading to failure in engineering parts is dealt with by Dr. U. R. Evans, the effects of the rate of loading on fracture by Dr. C. Gurney, and brittle fracture in mild steel by W. Barr. Each of these is in its own way an almost ideal summary, as would be expected from men each of whom in his own line can speak with outstanding authority. 'This little book, in fact, represents one of the most interesting publications in the realm of engineering metallurgy which has appeared in Great Britain for some time.

\section{Experimental Parasitology}

A NEW quarterly journal, Experimental Parasitology, published by Academic Press, Inc., of 125 East 23rd Street, New York 10, N.Y., will be launched this summer, with Dr. D. R. Lincicome, of Stine Laboratories, Newark, Delaware, as managing editor, and an editorial board composed as follows: Drs. H. H. Anderson, T. von Brand, E. Bueding, A. C. Chandler, E. C. Faust, Q. M. Geiman, G. van Grembergen, C. G. Huff, A. Lwoff, J. Oliver-Gonzalez, C. B. Philip, W. P. Rogers, J. D. Smyth and N. R. Stoll. Original papers dealing with the experimental approach to problems in the field of parasitology will be considered for publication, and contributions that involve experimental aspects of physiological, metabolic, biochemical, nutritional and chemotherapeutic problems of parasites and host-parasite relationships are especially desirable. In addition to original research material, a section of the periodical will be devoted to "Parasitological Reviews", which will consist of review articles prepared by invitation of the editors and covering all espects of the field. Manuscripts may be submitted to the managing editor or to any member of the board of editors.

\section{Electrical Engineering Course for Aeronautical Students}

THe College of Aeronautics, Cranfield, is starting a two-year course in electrical engineering, the aim of which is to give postgraduate students a grounding 